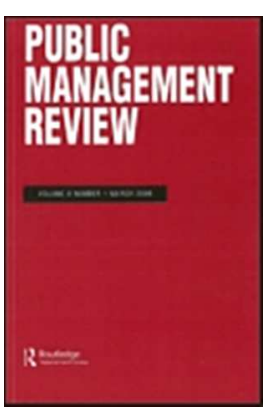

\title{
Engaging with Complexity in a Public Programme Implementation
}

\begin{tabular}{|r|l|}
\hline Journal: & Public Management Review \\
\hline Manuscript ID & RPXM-2016-0245.R1 \\
\hline Manuscript Type: & Special Issue Paper \\
\hline Keywords: & $\begin{array}{l}\text { complexity, interpretive lens, public programmes implementation, one-stop } \\
\text { shop, Local Government reform }\end{array}$ \\
\hline
\end{tabular}

\section{SCHOLARONE" \\ Manuscripts}




\title{
Engaging with Complexity in a Public Programme Implementation
}

\begin{abstract}
The study addresses the misalignment of locally implemented outcomes with centrallydefined programme objectives, applying a complexity-based lens as the heuristic device. The aim is to wade past the dominant use of metaphors into the deeper conceptual waters of emergence, coevolution, self-organisation. Combining the reinterpretation of extant literature with the analysis of an exemplary case, the paper delivers useful insights which lead the authors to argue that policy implementation must be approached pragmatically as a self-organising system, and that the way forward for the public managers of multi-organisational environments is to strategically engage with complexity.
\end{abstract}

Keywords: complexity, interpretive lens, public programmes implementation, one-stop shop, Local Government reform

\section{Introduction}

Complexity is the science of organisation - especially its origin and evolution - and is therefore the natural framework for considering organisation and connected entities (Haynes, 2015; Langley, 1999; Maguire, Allen, \& McKelvey, 2011, p. 3). The complexity approach is of particular interest to the organisational research because it offers a fundamentally new way to conceptualise and reframe the understanding of many of the phenomena common to the study of organisations (Mathews et al., 1999, p. 439). However, while the use of complexity theory in contemporary studies is increasing, complexity principles are still mostly used as a metaphorical device for creating new insights rather than as a means to understanding and managing organisations (Burnes, 2005), also in the political studies domain. This situation led Cairney (2012, p. 347) to argue that "the language of 'complexity' is used too loosely" to give meaningful advice to policy makers.

The study applies a complexity-based lens as the heuristic device to understand the misalignment of locally implemented outcomes with the centrally-defined objectives of a nationwide public programme in a country of 'Napoleonic' administrative tradition, illustrating and analysing the interaction between different tiers of government and the problems and difficulties of implementation and take-up. In the words of Peters, reforming the public machinery is always a challenging endeavour and is particularly "difficult, if perhaps not impossible in some instances" (Peters, 2008, p. 129). In southern Europe, as well as through the French colonial empire, the emphasis on codified law, on formality and on a centralised administrative organisation with a weak local self-government level has a pervasive influence in public reform trajectories (Kuhlmann \& Wollmann, 2014; Peters, 2008). While the dynamics and outcomes of change can be positive or negative in any context, the historical roots of the Napoleonic administrative system amplify the overall degree of organisational complexity and therefore require careful analysis to better grasp the public machinery's response to external perturbations. Hence, to avoid 'inappropriate simplification' (Haynes, 2015, p. xv) a holistic understanding is needed where a complexity-based interpretive lens must factor in these enduring legacies.

To illustrate why the local implementation of public policies varies from place to place, the paper adopts the position of Butler and Allen (2008), who link complexity thinking to organisational change. Following the original idea proposed in their study to discard a pure metaphorical use of complexity principles in favour of a conceptual clarification, the focus of this article is on emergence, co-evolution and self-organisation, three of the more common concepts of complexity that can be expected to kick in during programme implementation. These interrelated concepts and the way in which they interact are used to develop a framework for subsequent application and discussion. The paper seeks to: a) identify the key concepts of a complexity-based analytical approach; and b) break new ground by quasi-operationalising those concepts in the local implementation of a public programme. 
Specifically, the paper analyses the policy domain of administrative reform in Italy, in particular the local government implementation of the Sportello Unico per le Attività Produttive ('SUAP') Law introduced in 1998. The reform had the aim of reducing the daunting administrative burdens on businesses, making it mandatory for each of the country's $8000+$ municipalities to set up a One-Stop Business Shop as a single point of contact for firms to expedite the procedures to open, change or close of a business activity (Forti, 2000; Capano, 2003; Ongaro, 2004; OECD, 2009; Castelnovo, Sorrentino and De Marco, 2016). The SUAP therefore was tasked with streamlining the full business authorisation/licensing/permit process, including the coordination of all the public agencies involved (e.g., local healthcare authorities, fire brigade, provincial and regional governments, regional environment authorities).

The One-Stop Business Shop reform was devised as a highly complex, legalistic and laborious process that met with a hostile reception from the local governments, which forced the central government to impose increasingly harsher regulations. However, these interventions still failed to 'get the job done'. Indeed, Italy's administrative machinery remains highly fragmented, the SUAP public players continue to be poorly coordinated and incompatible techno-organisational solutions continue to multiply. Hence, to improve our understanding of the forces that have shaped the zig-zag implementation path and the outcomes of the SUAP reform, the authors decided to mine the Italian case for new and interesting insights using the complexity-based interpretive lens.

The qualitative paper proposes a twofold contribution to the extant literature that applies complexity thinking to the public sector. First, following Carney, it sets out to reduce the looseness of the language of 'complexity' used in the dominant metaphoric discourse by defining a 'quasioperationalisation' of emergence, co-evolution and self-organisation. Factoring these complexity concepts into the analysis of the implementation of the SUAP programme sheds new light on some of the phenomena common to public services experience (starting with the problematic interaction between the different tiers of government) and to evidence the mechanisms of policy change and the focal points for analysis of success or failure (Eppel, 2016).

Second, the paper advances the knowledge of organisational change in Napoleonic administrative systems given that, as noted by Cairney and Geyer (2015b), the studies on complexity thinking applied to the public sector address predominantly the Anglo-Saxon countries. Indeed, the fragmentation and heterogeneity of the administrative system and the often obsessively detailed law-making of the Napoleonic tradition make the Italian local government scenario a good case for critical study.

The authors therefore take a conceptual approach to respond to the paper's two key research questions:

\section{Q1. How can the concepts of emergence, co-evolution and self-organisation be operationalised starting with the analysis of the implementation of a nationwide policy programme? \\ Q2. To what extent does the complexity of the implementation process shape the direction and development of a public programme, in particular, in a country of the Napoleonic administrative tradition?}

The multi-tiered, legalistically bound Italian administrative system makes reform highly challenging for the recipient public organisations, which, to increase the programme's chances of success, are forced to put the management of complexity at the top of the agenda. The authors therefore argue that, instead of adopting a strategy to reduce complexity, the policy makers and implementers should engage with complexity to more effectively align the public service response, and to better understand the policy implementation process and dynamics (Allen and Butler, 2008; Rhodes et al., 2011; Cairney and Geyer, 2015a).

Methodologically, the paper adopts a qualitative approach to make sense of the different implementation outcomes of one specific reform, using the narrative strategy of process research (Langley, 1999) in which careful attention is given to how events develop over time. The qualitative 
process data used here are sourced from earlier studies conducted by the authors of this article, their personal experience in various implementation projects and documentary evidence.

Drawing on the various theoretical contributions which emphasise the need to push beyond the merely metaphorical concepts of complexity theory, the next section of the paper defines a complexity-based interpretive lens that enables a deeper exploration of the operational terrain on which public programmes are thrust. The exemplary case of Italy's One-Stop Business Shop (SUAP) is then discussed and mined extensively to inform answers to the two research questions. The final section presents the authors' conclusions, their initial reflections on the implications of complexity thinking for the public management practice, the limitations of the present study and future research development paths.

\section{Issues in complexity thinking}

Despite the growing number of studies that focus explicitly on complexity theories in the organisational domain, important questions still remain about the conditions that enable the effective applicability of those theories to the social domain (Stacey, 1995; Plowman et al., 2007; Byrne, 1998; Anderson, 1999; Duit and Galaz, 2008). In the strictly organisational sense, Levy (2000, p. 82) has already pointed out how complexity cannot simply be imported from the natural sciences and applied 'off-the-shelf' to industries and firms. Such an approach could generate translation errors mainly due to a lack in analytic clarity in conceptualisation (Gerrits and Meek, 2011), and lead different people to understand complexity, and seek to apply its insights, in very different ways (Cairney and Geyer, 2017). As Ghyczy (2003, p. 87) observes "it's tempting to draw business lessons from other disciplines - warfare, biology, music. But most managers do it badly". To which Richardson (2008) adds that many academics also 'do it badly'.

Cairney and Geyer (2015b) say that we should be careful about comparing the natural, physical and social worlds, unless we are content with the use of complex systems simply as metaphors. The use of metaphors within organisations is quite common and, argues Lissack (1997), the use of metaphor from complexity theory can change the way managers think about the problems they face, recast organisational processes in ways that inspire novel representations and guide managerial action. Maguire, Allen and McKelvey (2011) point out that the metaphors derived from the complexity theories are also an interpretive tool that promises real value for managers (Marks and Gerrits, 2013) to help elucidate some of the non-mechanistic, non-linear dynamics of organisations. Similarly, Lichtenstein (2011) says that complexity metaphors can be useful for helping us to picture the world in a more holistic, dynamic, and unpredictable way. However, by critically discussing the use of complexity metaphors in the organisational domain, Burnes (2005) concludes that it is difficult to claim that complexity theories have the potential to bring about a fundamental re-evaluation of the nature, purpose and operation of organisations, unless it can be shown that a complexity-based approach "is able to resolve the problems of managing and changing organizations more effectively than other approaches that are on offer" (p. 87).

Using complexity simply as a metaphor risks reducing it to just shorthand for complicated, instead of using complexity concepts as tools to elucidate "the mechanisms through which microlevel events and interactions can give rise to macro-level system structures, properties and behaviours" (Maguire, Allen and McKelvey, 2011, p. 9). To be really useful, metaphorically derived assertions about organisations have to be exposed to empirical scrutiny in order to lay the foundations of an alternative conception of organisation and management.

Applying complexity theory in an empirical study led Houchin and MacLean (2005) to observe that complexity theory is only partially successful as a device for describing organisational development and change. The limitations that have surfaced in the complexity thinking applied to empirical cases have been known for some time (Cairney, 2012; Krolczyk, Senf and Cordes, 2010; Klijn, 2008; Maguire, Allen and McKelvey, 2011). Cherry (2014, p. 42), for example, notes that these "remain abstract and have rarely been operationalized in ways that make a difference to 
practice". In fact, the meaning and implications of complexity have been less commonly elucidated, and rarely tested through empirical study. According to these scholars, the application of the complexity theories in the organisational domain remains abstract and informed by universal principles, which makes them applicable to a wide range of phenomenon areas with the drawback of being not very 'practical' (Krolczyk, Senf and Cordes, 2010).

Klijn (2008) highlights the need for an empirical operationalisation of the complexity concepts to make them applicable in the study of empirical phenomena. The 2008 special issue of the Public Management Review on "Complexity Theory and Public Management" was a first move in this direction but empirical analysis using complexity theory concepts in public administration is still relatively scarce (Maguire, Allen and McKelvey, 2011), leaving much work still to be done.

Cairney and Geyer $(2015 \mathrm{a}, \mathrm{b})$ observe that the application of complexity theory in the organisational domain will only be valuable if it can produce some results, which involves more the application of 'complexity thinking' to the study of real world problems than the use of rigid theoretical frameworks. The authors argue for a pragmatic approach that "involves a recognition and acceptance of the limits of our knowledge and understanding, and ability to gather evidence, developing models when we know that they only tell us part of the story" (p. 459).

In order to "facilitate organizational academics and practitioners in 'seeing' the complexity inherent in socio-technical organizations" (Richardson, 2008, p. 20), a complexity-based interpretive lens is one way to apply a complexity thinking approach to look at real world problems. Developing a complexity-informed lens for public policy analysis means identifying which existing complexity concepts can ensure the most coherent design (Eppel, 2012). Fortunately, the leading scholars to apply complexity thinking to the public domain have narrowed down the literature's many variations on the theme to a manageable number of underpinning concepts. For example, Richardson (2008, p. 14) observes that the existence of non-linear feedback in complex systems that allows for emergence, self-organisation, adaptation and learning has become synonymous with complexity thinking. Carney and Geyer (2015a) assume interdependency, co-evolution, positive and negative feedback, path-dependency, emergence and punctuated equilibrium as the complexity theory's main features. Eppel, who has worked the hardest to apply complexity thinking to the empirical analysis of real cases of nationwide public sector reform programmes, develops a complexity-based analytical lens that includes the concepts of components interaction, co-evolution and adaptation, feedback, emergence and self-organisation, far from equilibrium, and pathdependency (Eppel, 2012; 2016).

Following an approach similar to the one advocated by Eppel (ibidem) and Rhodes et al. (2011), the authors of this paper apply a 'complexity thinking' approach to analyse the on-theground implementation of a specific public reform programme in a country of Napoleonic administrative tradition. The aim is not to formalise a theory but, rather, to develop and test the analytical potential of a complexity-based interpretive lens in a real-world case. Accordingly, the paper provides the empirical descriptions needed to interpret the complexity factors at work and the main forces that shaped the Italian SUAP trajectory. More specifically, it demonstrates how the concepts of emergence, co-evolution and self-organisation enable a deeper understanding of the peculiar path trodden, which otherwise risks looking like the cumulative effect of a series of legislative interventions not always coherent in and among themselves (Castelnovo, Sorrentino and De Marco, 2016). The paper will exemplify how these fundamental complexity concepts take concrete form in the reality, surpassing their simple metaphorical use in the next, logical step towards their quasi-operationalisation.

\section{Conceptual model of a generic implementation process}

This section describes a conceptual model of a generic public policy implementation process based on the complexity concepts identified immediately above. Space limitations mean the authors are 
unable to conduct a systematic, comprehensive review of the relevant literature on public policy implementation here. Instead, the most critical forces at work are cited as a preliminary clarification of the ways in which a complexity-based interpretive lens can inform the two research questions. This pragmatic approach focuses exclusively on mapping the route taken by a generic programme implementation process, from its starting point (the initial conditions) through to the desired outcomes, which led different agents to interact in unpredictable ways, generating possible deviations from the initial expectations (Teisman, 2008).

Rhodes (2008) and Klijn (2008) see agent interaction as a fundamental aspect of the implementation process, concluding that the combined actions of individual agents in the system lead to the emergence of new features that solidify and form the structures of the social system (Klijn 2008, p. 308). From a complexity perspective, the context-specific and socially constructed behaviour of the agents and their relations is what leads to uncertainty in the implementation of a public programme (Morçöl, 2012, p. 22). During the interaction, the agents adapt to each other, self-organise and co-evolve over time; these processes of self-organisation can lead to the emergence of entirely new and unpredictable results (Eppel, Matheson and Walton, 2011).

As highlighted by Klijn (2008), dynamics in systems often show signs of unstable or at least temporarily stable situations that can be suddenly disrupted (what complexity theorists call 'punctuated equilibrium' [Teisman, 2008; True, Jones and Baumgartner, 2007; Bryan, and Baumgartner, 2012]). Activating a central government policy programme can create significant organisational and financial costs for the local implementers. As observed by Jacobs and Weaver (2012, p. 12): "where policy imposes costs on actors, those actors may adjust their behavior and invest in patterns of activity in ways that minimize the burdens that they face". The need to adapt to the new legislative and regulatory requirements creates conditions of disequilibrium to which the organisation's implementers respond by activating processes of adjustment, co-evolution and selforganisation, which, in turn, can generate new configurations, new behaviours and new practices, even though these do not fully correspond to those originally envisaged.

Houchin and MacLean (2005) observe that the 'natural' tendency of a complex social system is the creation of equilibrium rather than novelty, which seems particularly true in the case of highly regulated administrative systems, such as those of the risk-averse Napoleonic tradition. Therefore, if the interaction among the implementation process agents produces a new situation of equilibrium, the organisation will tend to maintain that state, at least until other conditions materialise that force it back to its previous state of disequilibrium.

The dynamic between temporary states of equilibrium and disequilibrium can be described as feedback loops. In fact, Bryan and Baumgartner (2012, p. 3) note that "policymaking is a continual struggle between the forces of balance and equilibrium, dominated by negative feedback processes, and the forces of destabilization and contagion, governed by positive feedback processes".

When the local implementers work towards achieving the desired new state defined by the policy, a positive feedback loop is generated that reinforces and amplifies the intervention's potential to transform the organisation (Houchin and MacLean, 2005). Vice versa, when the action of the local actors is opposed to achieving the desired new state a negative feedback loop is generated, which tends to reduce if not annul the policy's potential to transform the organisation. When this latter condition materialises, it may be necessary to rethink programme implementation and search for new alternatives (Jacobs and Weaver, 2012). Typically, to keep the programme on its proper course the government intervenes to adjust and/or reinforce the relevant norms, or to reduce the number and influence of the implementers. Consequently, in real-life systems, both negative and positive feedback loops operate together (Morçöl, 2012, p. 100). In particular, if negative feedback loops predominate, a system will be more stable. Conversely, the positive feedback loop prevails when "the exponential growth or decline in a system" (ibidem) induces the implementer organisations to embark on adaptation and transformation processes designed to restore a new situation of (temporary) equilibrium. 
Fig. 1 offers a rough guideline to the relational dynamics engaged in by the major forces on the ground that both reinforce and constrain change in the functioning of a generic programme implementation cycle, considering both positive feedback loops (left side) and negative feedback loops (right side). In Morçöl's words (2012, ibidem), the two kinds of loops are the 'engines' of self-organisation, co-evolution and emergence.
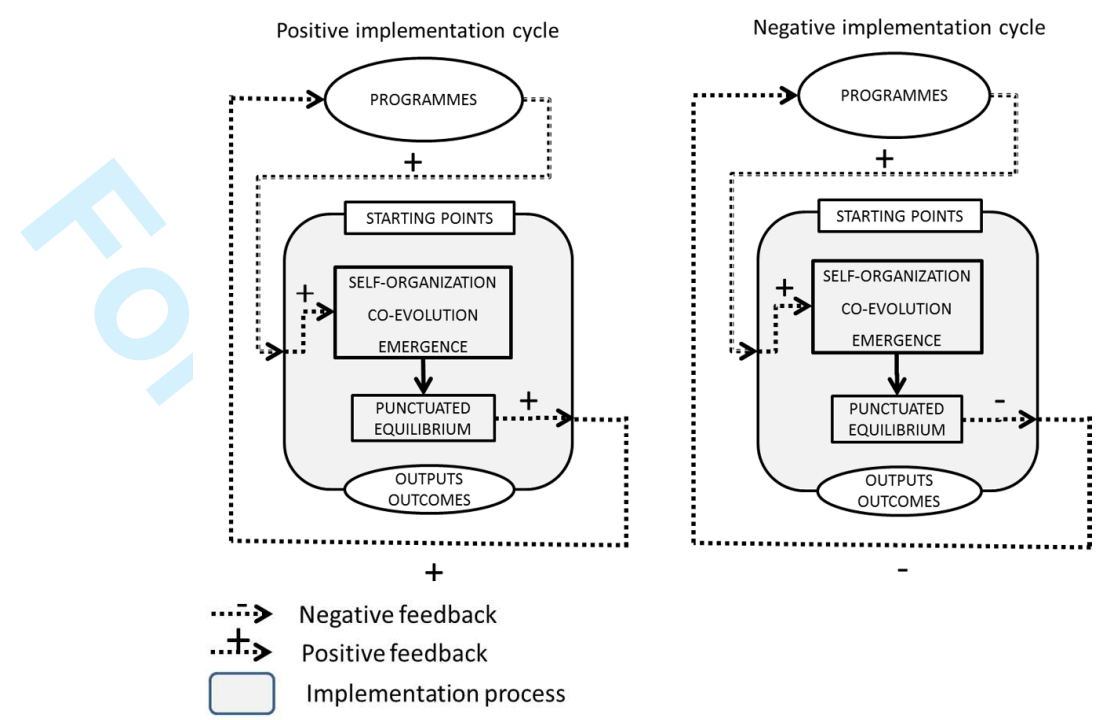

Figure 1. Conceptual model of a generic implementation process. (Source: the authors)

Having identified the major ground forces at work and the key assumptions that underpin the adoption of a complexity-based view, the following section applies the conceptual model proposed here to a real-life case. Basically, the analytical approach used is similar to the examples applied by some authoritative contributions, such as:

- The implementation of local government reform programmes (Haveri, 2006);

The implementation of housing policies in the UK (Butler and Allen, 2008);

- The implementation of infrastructure programmes in the UK (Teisman, 2008);

- The implementation of policies for tertiary education in New Zealand (Eppel, 2010; Eppel, Turner and Wolf, 2011);

- The study of leadership (Lichtenstein and McKelvey, 2011);

- The study of urban regeneration projects and healthcare information systems in Ireland (Rhodes 2008; Rhodes et al. 2011).

- The implementation of health-care reform in the US (Jacobs and Weaver, 2015).

The aim of the paper is to pursue the path taken by these notable antecedents with a contribution that sheds light on how, in the context of an administrative tradition heavily weighted to a legalistic approach such as Italy, emergence, co-evolution and self-organisation are key concepts that can help to better explain the dynamics that influence the extent and direction of policy implementation.

\section{An exemplary case: analysis of a nationwide reform programme}

Research (see, for instance [Klijn, 2008; Cairney, 2012; Maguire, Allen and McKelvey, 2011]) has pointed out the relative scarcity of complexity theories (or complexity perspective) applied to reallife empirical cases, especially in studies of the implementation of broad-scope public policies. This 
section uses the case of Italy's One-Stop Business Shop to show how a theoretical account of the three interrelated complexity factors of self-organisation, co-evolution and emergence can make sense of many of the facts at hand. The discussion of the case as a narrative strategy of qualitative process research (Langley, 1999) elucidates the reform's timeline.

\section{The Italian One-Stop Business Shop: overview}

The purpose of Italian Law 447/1998, otherwise known as the SUAP or One-Stop Business Shop programme, was to streamline the country's highly-fragmented and complex scenario of lengthy business authorisation, licensing and permit procedures whereby each Italian council was free to apply the protocols, forms and tariffs deemed the best fit for their constituency (Forti, 2000). Specifically, the SUAP called for each Italian municipality to establish a single point of contact (the One-Stop Business Shop) for firms to expedite all the official requirements for opening, changing or closing a business activity (Ongaro, 2004; OECD,2009). In particular, the single organisational unit of the one-stop business shop had to both coordinate all the relative local public bodies (e.g., health care service, fire brigade, provincial and regional governments, regional environmental department) and manage the relevant administrative procedures through either: i) in-house; or ii) joint-management via inter-municipal cooperation. At the time, Italy was gripped by a devolutionary trend that aimed to strengthen local organisational autonomy and enable the transfer of competences, hence, the legislator left it to the councils decide which form was the most appropriate (Capano, 2003).

To comply with Law 447/98, the councils therefore had to put together the pieces of a complex organisational puzzle that often demanded capabilities and resources they did not have. So it is hardly surprising that law-making alone failed to either deliver the goods or the expected outcomes of simplifying the authorisation procedures and easing the bureaucratic load on businesses (Castelnovo, Sorrentino and De Marco, 2016). Continuous SUAP adjustments were then written into law by successive governments, with two goals: i) to force all the municipalities to activate a one-stop shop; and ii) to leverage technology to transform the SUAP into a more simplified virtual service centre. Figure 2, below, snapshots the SUAP's legislative timeline.

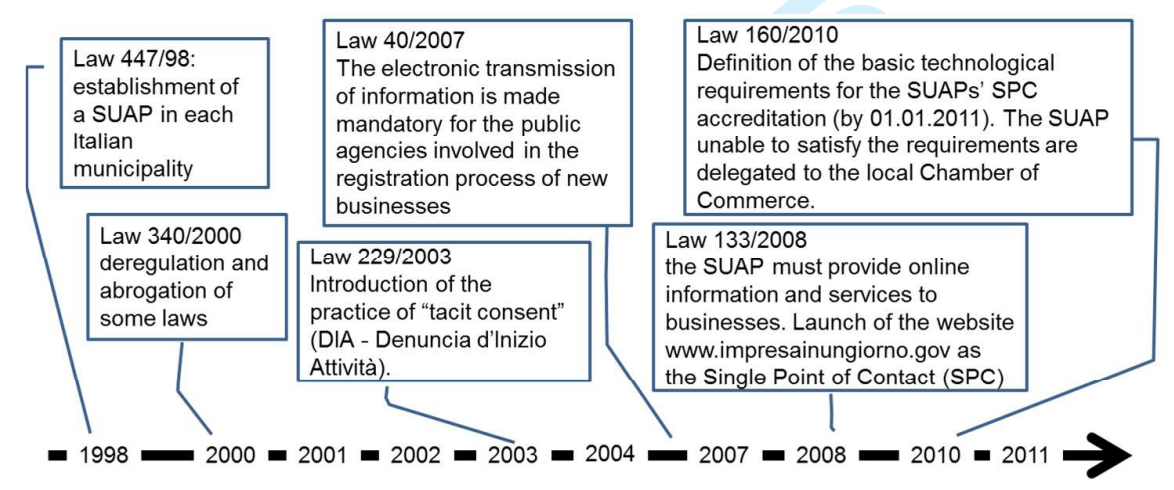

Figure 2 - SUAP programme legislative timeline. (Source: the authors)

The stream of legislation outlined in Figure 2 was driven by the central government's need to 'neutralise' local resistance and to clear the way for a fully operational SUAP. The 1998-2010 period can be described as a negative implementation cycle (see Figure 1, right-hand column), given that most of the local governments either just ignored the laws (there being no penalties for non-compliance) or merely paid lip service by going through the formalities of setting up a SUAP without effectively operationalising it. Both factors indicate a negative feedback loop stemming from the local governments' resistance to change, or even their very real inability to manage the change. Only a few local governments pro-actively stepped up to the SUAP plate, launching 
organisational transformation strategies that delivered an operationally effective SUAP (positive feedback loop).

In fact, it took the not-so-gentle nudge of Law 160/2010 to get the desired effects of the SUAP programme to finally kick in - 16 years after its 1998 launch date - with 8014 of Italy's total 8092 councils reporting a fully on-stream SUAP in 2014. Even then, Law 160/2010 did not come without a price, given that it forced those councils already running an effective, full-scope One-Stop Business Shop to delegate management to the local Chamber of Commerce if their technological and organisational solutions failed to meet the central government's new requirements.

\section{Complexity factors at work}

Italy's SUAP programme, the flagbearer of the policies to simplify the state's administrative machinery through ICT, was the central government's response to the EU's prodding to implement digital government. The scale and scope of the SUAP reform and the fact that its success was entirely dependent on whether the councils had the resources/funds to ensure the system could operate and fulfil its mission makes it a particularly interesting case study. In fact, the central government's law-makers not only failed to conduct the due diligence needed to learn whether the local implementers possessed the necessary technological, organisational and administrative governance capabilities, but also neglected to ensure any form of governmental control. This 'hands-off' approach effectively dumped the job of implementation squarely onto the councils, leaving them to deal with it alone as best they could, and led the feedback mechanisms to shape the pre-2010 implementation phases of the SUAP programme ( $\rightarrow$ self-organisation - A1). (The reason for codifying the 'complexity factors at work' identified in this section (A1, B2, C3, etc.) is to clarify the quasi-operationalisation of the complexity concepts in Table 1 of the next section: Discussion and implications.)

The multi-actor, inter-sector and inter-institutional SUAP reform was hoisted onto a highly fragmented, heterogeneous administrative stage where the actors (especially the smaller townships, about $75 \%$ of Italian municipalities) are rarely endowed with the means to manage complex processes of system innovation. Indeed, not only did few of Italy's local governments have the capabilities to manage the changes required by the SUAP law, many of those that embarked on organisational change to comply with it adapted the national norms to their specific local contexts $(\rightarrow$ self-organisation $-\mathrm{A} 2$ ). Thus, in open defiance of the government's interventions to create a fully standardised one-stop business shop network, the variegated mix of small and large townships that makes up Italy's municipal landscape led to the adoption of highly different approaches to develop and operationalise the SUAP.

In fact, the implementation of the One-Stop Business Shop has led to the practice of those behaviours defined by Butler and Allen (2008) as self-organising since "national policy is reinterpreted at the local level, with each local organisation uniquely mixing elements of national policy with their own requirements" (p. 421). Created as organisational structures, many SUAPs emerged spontaneously from the interaction of agents following their local rules and responding to feedback from other agents and their environment $(\rightarrow$ self-organisation - A3; emergence $-\mathrm{B} 1)$, without central direction, manipulation or control, central government policies or rules notwithstanding ( $\rightarrow$ emergence - B2). This explains why, to comply with the SUAP law, some small councils delegated management to a nearby, similarly sized counterpart or to their Comunità Montana (or the Provincial government) or chose to use voluntary aggregations of municipalities or public services companies.

The high degree of variation in the Italian SUAP system (macro-level) as a result of the interaction of the local agents (micro-level) is diametrically opposed to the goal of maximum standardisation set by Law 447/1998, highlighting two aspects of SUAP implementation typical of emerging phenomena: 'micro-macro effect' and decentralised control. ( $\rightarrow$ emergence - B3)

Italy's legalistic administrative tradition (typical of the Napoleonic model) causes the central government to use rigid regulatory frameworks to design and plan system innovation/reform 
processes. This compliance-driven route forced the local SUAP implementers to interact to define the intra- and inter-organisational workflows and, where possible, to consolidate common practices into uniform, standardised online procedures ( $\rightarrow$ co-evolution $-\mathrm{C} 1)$; some agents even had to review their internal operational procedures or reconfigure their organisational units. Hence, those councils and local agents who successfully implemented a SUAP embarked on a mutual adaptation process that produced organisational solutions which also met the needs of the context, even though these sometimes strayed from the legislator's implicitly defined model. ( $\rightarrow$ co-evolution $-\mathrm{C} 2$; selforganisation - A4).

The process of co-evolution/adaptation was promoted by specially appointed local "Coordination Committees" that, in bringing together the SUAP agents and other local stakeholders, introduced new players and new roles to the One-Stop Business Shop scenario $(\rightarrow$ emergence - B4). These local 'taskforces', which were not part and parcel of the SUAP law but the spontaneous result of emergent processes, actively participated in both the development of staff training courses ( $\rightarrow$ co-evolution - C3) and the standardisation of inter-organisational procedures and workflows to align them with the organisational solution adopted ( $\rightarrow$ emergence - B5).

The different methods used by the local implementers to adapt the SUAP to the context of jurisdiction resulted in a proliferation of organisational models and solutions of every kind. To correct this drift, Italy's central government wrote new laws (see Fig. 2 for the timeline) to restrict the organisational autonomy of the local governments, which it ruled a source of complexity and an impediment to the realisation of the one-stop business shop. In particular, the new laws:

- weakened the power of the councils to manage the SUAP procedures at their own discretion (for example, by introducing the practice of tacit consent);

- centralised specific, mainly front-office activities (for instance, through the setting up of the Single Point of Contact (SPC) as per the EU directives);

- defined the technological and organisational requirements that each SUAP needed to be recognised as fully operational, disqualifying the non-compliant municipalities from its independent management;

- allowed the councils to voluntarily delegate the SUAP's operations to the local Chamber of Commerce, making it mandatory for the disqualified non-compliant.

The hard line taken by the government completely disregarded the proven efficiency and effectiveness of certain local organisational models, signalling the demise of, for example, the associated SUAPs managed by public services companies, the SUAPs set up by the Comunità Montane on behalf of their municipal members and the associated SUAPs managed by aggregations of municipalities, dismantled in the case they did not comply with the new regulations. The constant rolling out of laws, rules and regulations that crushed the existing SUAP system can be attributed to two main factors: i) the poor coordination between the SUAP and other sector laws and regulations related to the business of the councils (in particular those of inter-municipal cooperation); and ii) the government's attempt to impose tighter, more direct controls on the implementation process, possibly contradicting certain mainstays of the national One-Stop Business Shop policies embedded in the original 1998 SUAP act.

However, despite the government's attempts to use the power of the law and ongoing regulatory adjustments to get the local implementers to adopt uniform solutions, at the time of writing, 18 years later, the Italian SUAP network is still fraught with complications. The implementation process has turned into a drawn-out narrative in which a wide range of organisational solutions have become doable, one example being the option introduced by Law $160 / 2010$ to delegate the SUAP to the local Chamber of Commerce. Interestingly, this 'emerging' solution was not on the cards when the reform first took flight and is in stark contrast to the goals of Law 447/1998 to strengthen the role and autonomy of the councils and to reduce the levels of intermediation between business and the PA. The fact that Law 160/2010 turned the SUAP tide is 
attested by the fact that $40 \%$ of the SUAPs were in the hands of the local Chamber of Commerce in 2014, which is a clear sign of self-organisation and emergence, although that indicator is subject to major variations of $0 \%$ to $89 \%$ at the regional level.

\section{Discussion and implications}

The sharp twists and turns of the SUAP reform path illustrate many of the analytical points made in this article, including "the indeterminacy of organizational systems and the difficulty with isolating cause and effect" (Haynes, 2015, p. 19) and non-linearity effects that make it hard to predict trends, particularly in the longer term (ibidem, p. 22). A combination of these factors and the intrinsic limitations of complexity thinking, because complexity theory is not a fully articulated theory (Morçöl, 2012, p. 262), help explain the strong tendency of scholars to use metaphors to describe complexity principles.

This study tries to break through the metaphorical boundaries on the premise that the inherent complexity of public programmes is linked to their state of constant flux, which, in turn, is driven by conditions of feasibility and the actions and interactions of the agents. It therefore stands to reason that a programme can have many potential outcomes which often diverge from the initial expectations and that rigid theories and simple legalistic conceptions of implementation are inadequate for understanding what happens on the ground (Peters, 2015, p. 90).

In the exemplified case of Italy's One-Stop Business Shop reform, the mix of co-evolution, self-organisation and emergence emphasises the non-linearity of the paths taken by the local implementers to comply with a centrally designed programme, highlighting, without getting lost in the too-specific details, how these major ground forces interact in an empirical setting. To achieve the aims set out at the beginning of the paper, the insights gleaned from the analysis can help piece together the answers to the two research questions.

\section{Q1. How can the concepts of emergence, co-evolution and self-organisation be operationalised starting with the analysis of the implementation of a nationwide policy programme?}

Table 1 summarises the conditions that led to self-organisation, co-evolution and emergence during the implementation of the SUAP reform and lays the foundations for a quasi-operationalisation of these concepts.

\begin{tabular}{|l|l|l|}
\hline $\begin{array}{l}\text { Key } \\
\text { Complexity } \\
\text { Concepts }\end{array}$ & $\begin{array}{l}\text { SUAP- } \\
\text { specific } \\
\text { Complexity } \\
\text { Factors }\end{array}$ & Example of conditions that shaped the implementation of the SUAP \\
\hline $\begin{array}{l}\text { Self- } \\
\text { organisation }\end{array}$ & A1-A4 & $\begin{array}{l}\text { A local agent (or group of agents) introduces implementation methods } \\
\text { not envisaged by the original programme design (e.g., delegating } \\
\text { management to the Comunità Montane or public services companies). } \\
\text { An agent (or group of agents) identifies and involves other agents in } \\
\text { the implementation process not envisaged by the original programme } \\
\text { design (e.g., the provincial governments, the Comunità Montane or } \\
\text { public services companies). } \\
\text { An agent (or group of agents) identifies and makes improvements to } \\
\text { the implementation process not envisaged by the original programme } \\
\text { design. } \\
\text { (e.g., involving the local stakeholders in the governance of the } \\
\text { implementation process). }\end{array}$ \\
\hline Emergence & B1-B5 & $\begin{array}{l}\text { Organisational structures/units not envisaged by the original } \\
\text { programme design (e.g., the formation of local committees of } \\
\text { coordination). }\end{array}$ \\
\hline
\end{tabular}


- Organisational roles not envisaged by the original programme design (e.g., delegation to the local Chambers of Commerce as per Law 160/2010).

- Reorganisation of the workflows according to methods not envisaged by the original programme design. (e.g., the redesign of the many intra-organisational workflows and the domino effect on the different inter-organisational workflows of the SUAP-related public agencies.)

- An agent changes its structure and/or behaviour in response to the behaviour of another agent during the implementation process (e.g., all the actors involved launch internal reorganisation processes to better support the SUAP activities).

- The implementer agents, or some of them, agree to adopt joint operational methods that require changes not needed when each works in isolation (e.g., the mutually acceptable definition of local operational rules and standards).

- An agent (or group of agents) sets in motion actions to reduce heterogeneous factors as a condition to improve the implementation process (e.g., the joint issuance of training courses by different public agencies affected by the implementation process).

Table 1. Quasi-operationalisation of the complexity concepts. (Source: the authors)

\section{Q2. To what extent does the complexity of the implementation process shape the direction and development of a public programme, in particular, in a country of the Napoleonic administrative tradition?}

The implementation and outcomes of the SUAP programme were the result of the dynamic tension between two opposing visions: that of the central government's 'planned' and intrinsically rationalist 'innovation by law' method, consisting of continual interventionist adjustments to increase its control and direction of the results throughout; and that of the local government implementer's more contingent approach, oriented to the real-life (contextually defined) constraints and opportunities of complying with the law. The SUAP case sheds much light on the interaction between these two conflicting fixed views, which, due to Italy's strong legalistic tradition of governance, has led to pervasive co-evolution and self-organisation and, via the relative feedback loops, shaped the material implementation of the reform. Interestingly, the co-evolutionary relations occurred at two levels: between the actors and between the policies. This medley of dynamic interactions has foiled the central government's repeated attempts to force the councils to adopt a single business model that would reduce the complexity of the system. The current SUAP network continues to deploy multiple organisational solutions, including directly operated, associated management and delegation to the Chamber of Commerce, therefore confirming the view of Christensen and Lægreid (2012, p. 5) that complexity is "a systemic feature of public sector organisations that needs to be taken into consideration when reorganising the administrative apparatus, rather than regarding it as a disease that must be eliminated". In other words, to implement public reforms it is necessary to rewrite the rules to engage with complexity rather than trying to reduce it (Rhodes et al. 2011, our italics).

Engagement is interpreted here as being realistic and taking on the challenge of problemsolving. Haynes (2015, p. 48) advice to "embrace complexity and grasp opportunities" is also an invitation to the policy makers and the public managers to chart a realistic course and to accept the changing nature of the systems in which they operate. Addressing wicked problems calls for public officials to forge new ways of thinking, leading, managing and organising which recognise the complexity of the issues and processes (Head and Alford 2015, p. 12); public officials also need to 
acknowledge that there are limits to their capacity to determine the outcomes and to control the direction that the emergence of new forms of order takes (Haynes 2015, p. 31).

To engage with complexity, the policy makers must, above all, break with the logic of best practices that still percolates in the public sector mindset. The complexity and heterogeneity of public organisations debunks the notion that a universal organisational Best Practice Plan (Butler and Allen, 2008) exists. As the SUAP case clearly shows, identifying a specific solution as the best practice to adopt (implicitly or explicitly) for defining the legal and regulatory norms of a reference model is no guarantee that its on-the-ground application will eliminate different and often unpredictable results.

To the public manager, engaging with complexity means retiring the governance and accountability model "based on assumptions of predictability, the elimination of uncertainty by planning and analysis methodologies and control by compliance" (Rhodes et al. 2011, p. 206) to bring on board a model that consents "frequent adaptation and a real time approach to navigating emergent reality - at all levels" (ibidem). Consequently, managers must "rethink the nature of hierarchy and control, learn the art of managing and changing contexts, promote self-organising processes, and learn how to use small changes to create large effects" (Burnes, 2005, p. 82). Moreover, complexity thinking negates the traditional (and misleading) separation between evaluation and implementation: "it is the feedback process itself that offers ... the best understanding of how performance is constructed" (Haynes, 2015, p. 86). Therefore, in order to identify critical issues and adjust the organisational processes, for instance, to reinforce feedback (ibidem, p. 149), it is necessary to first understand this two-way relationship.

Clearly, central government intervention alone will not solve the problem of translating the implementation strategies into concrete actions. So what is the deal here? What is the point of providing the implementers working in a complex operational environment with guidelines whose 'best answers' or 'golden rules' are, at most, only wishful thinking? One practical solution suggested by Haynes (2015) is to invite the managers at various levels to use the public values as a compass: "Values are at the core of public services and concepts of public intervention .... [they] attract social stability and order" (p. 146). Ultimately, embracing complexity is about "serving the community and the public interest" (p. 149).

This reference to values is clear but its reasonableness risks clashing with the dominant administrative logics which, as shown by the exemplary case of the SUAP programme, usually manage to ride out the storms without feeling the need to update the credo of 'how' to do reform. In other words, the case evidences that none of the governmental systems made any attempt to learn, that their response was merely to adapt, and that the stacking up of laws, rules and regulations only further complicated matters. Moreover, the public managers continue to be trained in mostly the legal-formal aspects of the national administrative tradition. Paradoxically, in legalistic administrative contexts like Italy, the law takes precedence over the value generated by the effectiveness of local emergent solutions. The government's reforms are seen as rigid obligations, not as opportunities to drive major change, which is what set Italy's One-Stop Business Shop reform on a turbulent journey that lasted almost 20 years.

\section{Conclusions and further research directions}

The paper goes against the grain of the metaphorical use of complexity principles in the mainstream literature to highlight the value of applying a complexity-based lens to the analysis of the implementation of a nationwide public reform. This initial scoping of the three concepts of emergence, co-evolution and self-organisation has flagged the potential threats to the operational success of such a programme unless it is recognised as a self-organising system that breeds emergence and co-evolution.

The study's findings point to a more pragmatic and advantageous way to deal with the nonnegotiable issue of the complex nature of multi-organisational environments, making a strong 
argument for the policy makers and the public managers to step off the merry-go-round of reducing complexity and to strategically engage with complexity.

This tentative bid to build a bridge between generalised complexity concepts and a specific case does not deliver absolute answers to the puzzling question of how to apply complexity theories to the public domain; it offers no direct guidance on how large-scale programmes can be implemented; nor does it provide evidence of the effectiveness of implementation (outcomes). Rather, the study sets the start line from which to develop complexity assessment systems capable of managing the instability of the external world effectively, and not to mirror (or co-align) it (à la Lawrence and Lorsh).

The overarching aim of the paper is to advance our current thinking by integrating different disciplinary perspectives that identify key interlinked factors worthy of further investigation. In particular, the authors acknowledge the paper's limitations, which translate into the need to: develop the framework of the conceptual clarification (merely outlined here, also due to lack of space); test the list of Table 1 for both comprehensiveness and parsimony; make a more in-depth analysis of the connections between emergence, co-evolution and self-organisation to help improve the descriptive scope of the model in Figure 1; and use other case studies to test and validate the proposed heuristic approach. Future research projects also will enquire more deeply into how the strategy of engaging with complexity ties in with Haynes's (2015) proposal of 'managing for values'.

Ultimately, the fact that the "generalisability of the information about complex systems is problematic" (Morçöl, 2012, p. 247) means empirical studies are needed to expand the knowledge gained from the single case and single-country research, and to enable the comparison of the approaches and results of different countries and different policy domains.

The research approach adopted here is a first attempt in what is necessarily a collective endeavour to glean useful insights from the application of a complexity-based lens.

\section{References}

Anderson, P. (1999). Complexity Theory and Organization Science, Organization Science, 10, 3 : $216-232$

Burnes, B. (2005). Complexity theories and organizational change. International Journal of Management Reviews, 7, 2: 73-90

Butler, M. J. R., and Allen, P. M. (2008). Understanding Policy Implementation Processes as SelfOrganizing Systems. Public Management Review, 10, 3: 421-440

Byrne, D. (1998). Complexity Theory and the Social Sciences. Routledge, London

Cairney, P. (2012). Complexity Theory and Political Science. Political Studies Review 10, 3: 346358

Cairney P. and Geyer, R. (2015a). Introduction: A New Direction in Policymaking Theory and Practice? In Cairney P., Geyer, R. (eds.), Handbook on Complexity and Public Policy (115). Edward Elgar, Cheltenham, UK

Cairney, P., Geyer, R. (2015b). Conclusion: where does complexity and policy go from here? In Cairney, P. and Geyer, R. (eds.) Handbook on complexity and public policy (457-465). Edward Elgar, Cheltenham

Cairney, P. and Geyer, R. (2017). A critical discussion of complexity theory: how does 'complexity thinking' improve our understanding of politics and policymaking? Complexity, Governance and Networks. (Forthcoming),

Capano, G. (2003) Administrative traditions and policy change: when policy paradigms matter. The Case of Italian administrative reform during the 1990s, Public Administration 81: 781-801. 
Castelnovo, W, Sorrentino, M. and De Marco, M. (2016). Italy's One-Stop Shop: A Case of the Emperor's New Clothes? In Rossignoli, C., Gatti, M. and Agrifoglio, R. (eds.), Organizational Innovation and Change (27-39), LNSIO 13. Springer, Berlin

Cherry, N. (2014). Organisational Paradoxes of Local E-government, Journal of Contemporary Issues in Business and Government, 20, 1: 41-57

Christensen, T. and Lægreid, P. (2012). Competing principles of agency organization - the reorganization of a reform. International Review of Administrative Sciences, 78, 4: 579-596

Duit, A. and Galaz, V. (2008). Governance and Complexity-Emerging Issues for Governance Theory. Governance, 21, 3: 311-335

Eppel, E. (2012). The application of a complexity analytical lens to understanding and explaining public policy processes. in Gerrits, L. and Marks, P. (eds.). COMPACT I: Public Administration in Complexity (174-197). Emergent Publications, Litchfeld Park.

Eppel, E. (2016). Complexity thinking in public administration's theories-in-use. Public Management Review. Published online: 03 Nov 2016.

Eppel, E., Turner, D. and Wolf, A. (2011). Experimentation and learning in policy implementation: Implications for public management. Institute of Policy Studies Working Paper 11/04. Wellington, NZ. Victoria University of Wellington

Eppel, E., Matheson, A. and Walton, M. (2011). Applying Complexity theory to New Zealand public policy - Principles for Practice. Policy Quarterly, 7, 1: 48-55

Forti, A. (2000). Reduction of administrative burden for enterprises - the one stop shop experience in Italy. European Commission Peer Review Programme. Online: http://pdf.mutuallearning-employment.net/pdf/ind-exp-paper-it-nov00-p.pdf

Gerrits, L. and Meek, J.W. (2011). Propositions for Complexity Science. In Gerrits, L. and Marks, P. (eds.). COMPACT I: Public Administration in Complexity (350-363). Emergent Publications, Litchfeld Park.

Haveri, A. (2006). Complexity in Local Government Change. Public Management Review, 8, 1: 31 $-46$

Haynes, P. (2015). Managing complexity in the public services (Second ed.). Routledge. Abingdon

Head, B. W. and Alford, J. (2015). Wicked problems: implications for public policy and management. Administration and Society, 47, 6: 711-739

Houchin, K. and MacLean, D. (2005) Complexity Theory and Strategic Change: An Empirically Informed Critique. British Journal of Management. 16, 2: 149-66

Jacobs, A. M. and Weaver, R. K. (2012). Policy Feedback and Policy Change. Paper presented at the APSA 2010 Annual Meeting, Washington, D.C.

Jacobs, A. M. and Weaver, R. K. (2015). When Policies Undo Themselves: Self-Undermining Feedback as a Source of Policy Change. Governance, 28, 4: 441-457

Klijn, E.H. (2008). Complexity Theory and Public Administration: What's New? Public Management Review, 10, 3: 299-317

Krolczyk, A., Senf, C. and Cordes, N. (2010). Construction of a Complex Adaptive Systems Pattern as an Epistemological Lens for E-Government Systems. Proceedings of the $43^{\text {rd }}$ HICSS.

Honolulu, 5-8 Jan, 2010: 1-10

Kuhlmann, S., \& Wollmann, H. (2014). Introduction to comparative public administration. Edward Elgar, Cheltenham.

Langley, A. (1999). Strategies for theorizing from process data. Academy of Management Review, 24, 4: 691-710.

Levy, D.L. (2000). Applications and Limitations of Complexity Theory in Organization Theory and Strategy in Rabin, J., Miller, G.J. and Hildreth, W.B. (eds), Handbook of Strategic Management, Second Edition. Marcel Dekker, New York.

Lichtenstein, B. (2011). Complexity science contributions to the field of entrepreneurship, in Allen, P., Maguire, S. and McKelvey, B. (Eds.): The SAGE Handbook of Complexity and Management, 471-493, Sage, London 
Lichtenstein, B.B. and McKelvey, B. (2011). Four types of emergence: a typology of complexity and its implications for a science of management. International Journal of Complexity in Leadership and Management, 1, 4: 339-378

Lissack, M.R. (1997). "Mind your metaphors: Lessons from complexity science, Long Range Planning, 30, 2: 294-298

Maguire, S., Allen, P. and McKelvey, B. (2011). Complexity and Management: Introducing the SAGE Handbook. In Maguire, S., Allen, P. and McKelvey, B. (eds.) Complexity and Management (1-26). Sage, Los Angeles

Marks, P.K. and Gerrits, L.M. (2013). Approaching Public Administration from a Complexity Perspective. Public Administration Review, 73, 6: 898-903

Mathews, K. M., White, M. C., and Long, R. G. (1999). Why Study the Complexity Sciences in the Social Sciences? Human Relations, 52, 4: 439-462.

McKelvey, B. (1999) 'Complexity theory in organization science: seizing the promise or becoming a fad?', Emergence, 1, 1: 3-32

Morçöl, G. (2012). A complexity theory for public policy. New York: Routledge

OECD (2009). Better Regulation to Strengthen Market Dynamics - Italy 2009. Online: http://www.oecd-ilibrary.org/governance/oecd-reviews-of-regulatory-reform-italy2009_9789264067264-en

Ongaro, E. (2004). Process management in the public sector: The experience of one-stop shops in Italy. International Journal of Public Sector Management, 17, 1: 81-107.

Peters, B. G. (2008). The Napoleonic tradition. International Journal of Public Sector Management, 21, 2: 118-132.

Peters, B. G. (2015). Advanced Introduction to Public Policy. Cheltenham: Edward Elgar

Plowman, D.A., L.T. Baker, T.E. Beck, M. Kulkarni, S.T. Solansky and D.V. Travis. (2007). Radical Change Accidentally: The Emergence and Amplification of Small Change, Academy of Management Journal, 50, 3: 515-43

Richardson, K.A. (2008), Managing Complex Organizations: Complexity Thinking and the Science and Art of Management. E:CO, 10, 2: 13-26

Rhodes, M.L. (2008). Complexity and Emergence in Public Management: The case of urban regeneration in Ireland. Public Management Review, 10, 3: 361-379.

Rhodes, M.L., Murphy, J., Muir, J. and Murray, J. (2011). Public Management and Complexity Theory: Richer Decision Making in Irish Public Services, New York: Routledge

Stacey, R.D. 1995. The Science of Complexity: An Alternative Perspective for Strategic Change Processes, Strategic Management Journal, 16, 6: 477-95

Teisman, R.G. (2008) Complexity and Management of Improvement Programmes. Public Management Review, 10, 3: 341-359

Teisman, G.R. and Klijn, E.H. (2008). Complexity Theory and Public Management. Public Management Review, 10, 3: 287-297 